\title{
Congenital Chylothorax: Rapid and Effective Response to Polyvidone Iodine
}

\author{
F. M. R. Maoulainine", N. Elidrissi Slitine, L. Erguig \\ Neonatal Intensive Care Unit, Mother and child Pole, Mohammed VI University Hospital, Research Team for \\ Childhood, Health and Development, Medical School of Marrakesh, Cadi Ayyad University, Marrakesh, \\ Morocco \\ Email: fadl2020@hotmail.com
}

Received 18 November 2015; accepted 29 February 2016; published 3 March 2016

Copyright (C) 2016 by authors and Scientific Research Publishing Inc.

This work is licensed under the Creative Commons Attribution International License (CC BY). http://creativecommons.org/licenses/by/4.0/

(c) (i) Open Access

\begin{abstract}
Introduction: Congenital chylothorax, defined by the presence of chyle in the pleural cavity, is a rare congenital disorder of varying severity. The objective of this study was to report a case of idiopathic congenital chylothorax treated with povidone iodine effectively without side effects after failure of conservative treatment by chest drainage. Case presentation: A term female Newborn was admitted in the neonatal intensive care unit at $\mathbf{1 6}$ days of life, for respiratory distress. The Clinical examination objectified a Sliverman score of 3/10 with a pleural effusion syndrome. The chest radiography confirmed the pleural effusion and the analysis of the pleural fluid after aspiration confirmed the chylothorax, with a protein rate of $35 \mathrm{~g} / \mathrm{l}$, Triglycerids $37 \mathrm{mg} / \mathrm{L}$, and Leukocytes count was $1140 / \mathrm{ml}$ with $\mathbf{9 0 \%}$ lymphocytes. A chest drainage was performed on the seventh day but followed by the recurrence of the effusion. The use of $5 \mathrm{ml}$ of $4 \%$ povidone iodine in the pleural space as a chemical pleurodesis was performed. The clinical and radiological evolution was favorable after 24 hours without relapse or side effects such as allergic reaction or worsening of the respiratory condition. Thoracic ultrasound was performed after 15 days, having objectified minimal right side effusion measuring $5 \mathrm{~mm}$ maximum thickness. Conclusion: Chemical pleurodesis by the polyvidone iodine in the chylothorax appears to be affordable and effective, and needs to be more considerate in the conservative treatment of congenital chylothorax.
\end{abstract}

\section{Keywords}

Congenital Chylothorax, Polyvidone Iodine

\footnotetext{
"Corresponding author.
} 


\section{Introduction}

Spontaneous chylothorax is defined as an accumulation of lymphatic fluid or chyle in the pleural space. It is a rare condition representing $1 \%$ - 2\% of pleural effusions, with a prevalence between 1/8600 and 1/1500 birth [1]. The evolution is unpredictable sometimes leading to an important morbidity, denutrition, dehydration and immune deficiency [2]. The diagnostic is confirmed by the analysis of pleural fluid. The management extends from conservative treatment to surgery in some refractory cases. Some few cases of treatment with polyvidone iodine in congenital chylothorax were published [3]-[6]. We reported a case of congenital idiopathic chylothorax in which one pleural injection of povidone iodine stopped the pleural effusion promptly and effectively.

\section{Case Presentation}

A female baby admitted at 16 day of life, was delivered vaginally at 40 weeks of gestation, with a birth weight of 2970 g, her mother was primipara primigravida, aged 23 years.

The Clinical examination of the newborn on admission revealed a moderate respiratory distress quoted 3/10 by the Silverman score, and decreased breath sounds on the right side of the chest. The Saturation of oxygen was $90 \%$ on 1 l/min of oxygen. The chest X-ray (Figure 1) and CT scan revealed an important right-sided pleural effusion and signs of pulmonary infections.

A needle aspiration performed at the first day of admission revealed purulent fluid, with $90 \%$ of neutrophiles polynuclear and $10 \%$ of lymphocyts. The culture revealed an Enterococcus SPP multi-resistant, and responsive to only Teicoplanine, so the patient was treated with the association of teicoplanine Vancomycin ${ }^{\circledR}: 25 \mathrm{mg} / \mathrm{Kg}$ /12hours for 10 days and aminosids: $5 \mathrm{mg} / \mathrm{kg} /$ day during 3 days, this allowed the stabilization of her respiratory status. The second pleural aspiration, done before the drainage, showed a milky fluid. The drainage removed an average of $100 \mathrm{ml}$ of a chylous pleural fluid (Figure 2) per day during 13 days, with the following characteristics: protein $35 \mathrm{~g} / \mathrm{l}$, triglycerides $37 \mathrm{mg} / \mathrm{l}$, and 90\% lymphocytes. The Gram stain showed no bacteria and the culture was sterile. Tests of the thyroid function were normal, and serologic tests for toxoplasmosis, rubella, cytomegalovirus, herpes simplex virus, and syphilis, were negative. At day 13 of drainage, due to the persistant chylous fluid, a conservative treatment consisting of the intrapleural injection of $5 \mathrm{ml}$ of $4 \%$ concentrated polyvidone iodine (Betadine ${ }^{\circledR}$ ) was performed. The clinical and radiological evolution was good after 24 hours without recurrence. No adverse effects were noticed such as allergic reaction or worsening of respiratory status.

15 days later, a chest X-ray (Figure 3) showed no further accumulation of fluid and thoracic ultrasound showed a mild pleural effusion on the right side within one month. There were no signs of recurrence at follow-up visits.

\section{Discussion}

Congenital chylothorax is the most common cause of pleural effusion in the newborn [2]. It can be isolated or

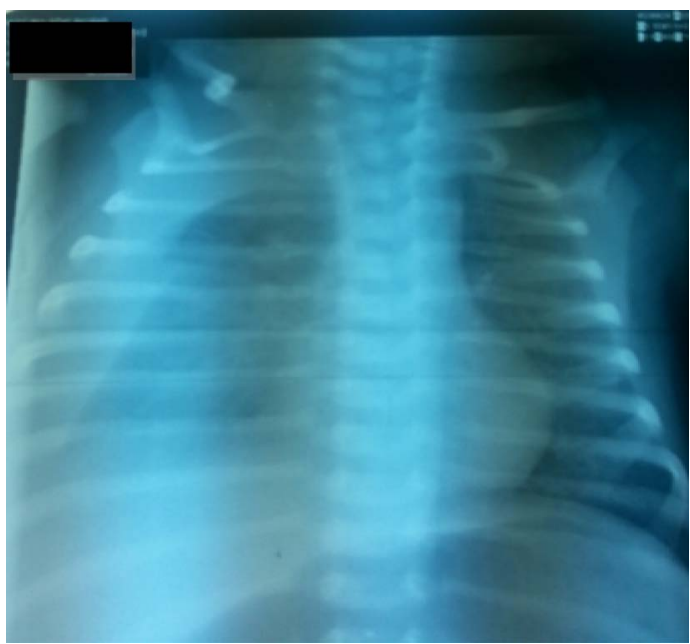

Figure 1. The chest X-ray performed at the admission showing a right pleural effusion. 


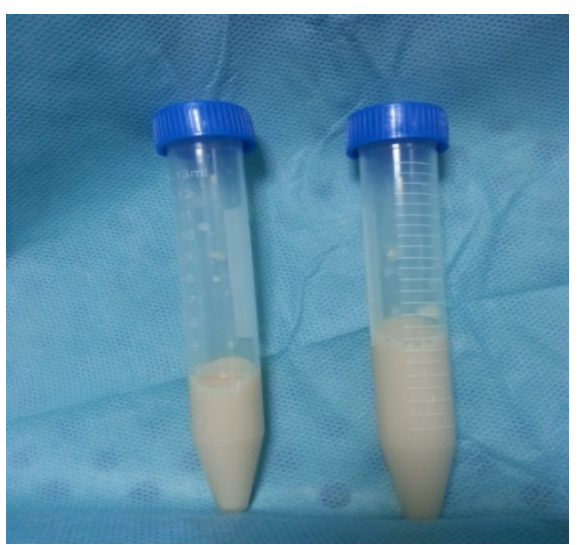

Figure 2. The chylous pleural fluid: “milk-like” appearance after pleural aspiration.

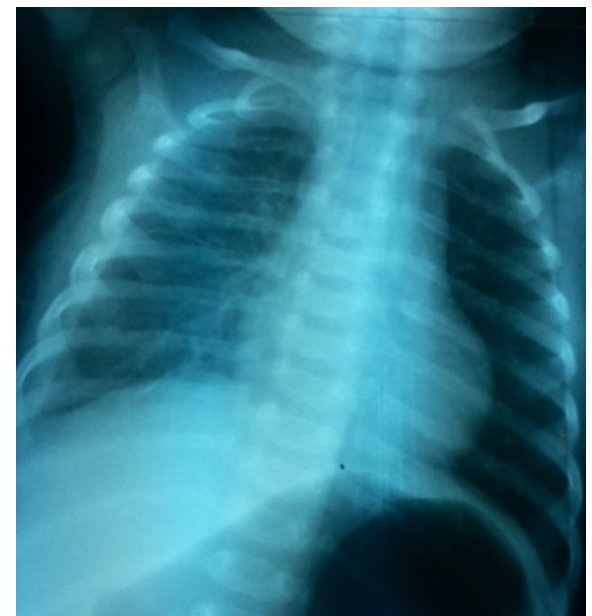

Figure 3. The chest X-ray performed after pleurodesis with Polividone-iodine.

associated with other abnormalities of the lymphatic system such as congenital pulmonary lymphagiectasia, a rare developmental disorder involving the lung and characterized by pulmonary subpleural, interlobar, perivascular and peribronchial lymphatic dilatation [6]. Congenital chylothorax may present at birth or develop during the first week of life, such us the case of this newborn. Some genetic conditions can be associated with congenital chylothorax: Down syndrome, turner syndrome and Noonan Syndrome, in this study no genetic exploration was done, but there were no clinical signs of genetic abnormalities [7]. Other diseases: congenital goiter, lung tumors, congenital lymphangiectasis, pulmonary sequestration, right diaphragmatic hernia and infections with cytomegalovirus, adenovirus or group B streptococcus [8], can also be associated. In this case, no pulmonary disease was identified, thyroid test were normal, and an enterococcus SPP was isolated in the pleural fluid. The diagnostic of congenital chylothorax is orientated by the chest radiography and CT scan, and confirmed by the analysis of the pleural effusion. In the absence of feeding, the diagnosis of chylothorax is based on criteria: pleural fluid protein concentration $>20 \mathrm{~g} / \mathrm{l}$, triglyceride concentration $>100 \mathrm{mg} / \mathrm{dl}$, number of cells per milliliter $>100$ with lymphocyte predominance, and sterile culture [9]. If the newborn was already fed, the pleural effusion becomes milky-appearance, indicating the presence of chylomicrons. The prevalence of lymphocytes in the drainage fluid is of major importance in the diagnosis since this finding is independent of nutrition.

Massive chyle depletion has profound effects on the immune system and involves a permanent risk of infection. Nutrition plays an important role in reducing lymphatic production [10]. Enteral nutrition with medium-chain triglycerides and total parenteral nutrition have been successfully employed. In this case, the parenteral nutrition was not possible due to shortage in the pharmacy of the hospital [10] [11].

The drainage should only be performed in symptomatic newborns and particularly in those requiring ventilation. The failure of the drainage can lead to the injection of the somatostatine or its analog, to a chemical pleu- 
rodesis and finally to surgery in the absence of response. But there is no consensus on wich product and when to start with. It is important to notice that often several of them are implemented simultaneously or sequentially [12]. Treatment is generally supportive.

The pleurodesis has its indications in cases of congenital CT refractory to conservative treatment and creates pleural adhesions by injection of irritating substances. Povidone-iodine used for this purpose, has been reported by very few teams, and appeared to be efficient [12]. In this case, Povidone-iodine was used for pleurodesis for its low cost and its affordability. It was reported that either topical iodopovidone applications or the use of iodine-based contrast agents may cause transient thyroid dysfunction. High concentrations of exogenous iodine are capable of blocking the organic-binding and coupling reactions and decrease thyroid hormone synthesis. Excess iodides may also induce thyrotoxicosis in susceptible individual [13]. Thyroid hormone (TSH, T4, T3) levels were routinely measured just before pleurodesis, and at 24 hours and 72 hours post pleurodesis [2]. In this case, as in the other reported, there was no significant alteration in thyroid function. Some cases of renal failure were reported. The respiratory function must also be monitored to watch the consequences of the pleurodesis. In this case, there were no renal toxicity and respiratory status was normal. Surgical treatment is indicated in case of the failure of conservative treatment [2] [6] [10] [13].

This report highlights the importance of considering the chemical pleurodesis when the control of pleural effusion is impossible with repetitive drainage. Polyvidone iodine seems to a good alternative to other chemical pleurodesis after ruling out renal insufficiency.

\section{Conclusion}

The chemical pleurodesis with polyvidone iodine is an effective and affordable conservative treatment, which can contribute to reducing the morbidity related to the prolonged hospitalization and repeated pleural punctures. Consensus precising the right concentration, the quantity and the number of pleurodsis by povidone iodine is missing, and can help in managing the congenital chylothorax based on every newborn condition.

\section{References}

[1] Al-Tawil, A.G., AL-Hathal, M., et al. (2000) Congénital Chylothorax. American Journal of Perinatology, 17, $121-126$. http://dx.doi.org/10.1055/s-2000-9281

[2] Hmami, F., Oulmaati, A., Bouharrou, A. et al. (2014) Chylothorax congénital: Une réponse rapide et totale à la polyvidone iodée. Archives de Pédiatrie, 3719, 1-4. http://dx.doi.org/10.1016/j.arcped.2014.06.006

[3] Brissaud, O., Desferere, L., Mohsen, R., et al. (2003) Congenital Idiopathic Chylothorax in Neonates: Chemical Pleurodesis with Povidne-Iodine. Archives of Disease in Childhood-Fetal and Neonatal Edition, 88, 531-533. http://dx.doi.org/10.1136/fn.88.6.F531

[4] Mitanchez, D., Salomon, R., Walter-Nicolet, E., et al. (2006) Congenital Chylothorax: What Is the Best Strategy? Archives of Disease in Childhood-Fetal and Neonatal Edition, 91, 153-154. http://dx.doi.org/10.1136/adc.2004.069690

[5] Murki, S., Fahhimuddin, M. and Gaddam, P. (2010) Congenital Chylothorax Successful Management with Chemical Pleurodesis. Indian Journal of Pediatrics, 77, 332-334. http://dx.doi.org/10.1007/s12098-010-0022-4

[6] Lahmiti, S., Elhoudzi, J., Baki, S., et al. (2009) Congenital Chylothorax Case Study. The Scientific World Journal, 9, 431-434. http://dx.doi.org/10.1100/tsw.2009.62

[7] Van Straaten, H.L., Gerards, L.J. and Krediet, T.G. (2007) Chylothorax in the Neonatal Period. European Journal of Pediatrics, 152, 2-5. http://dx.doi.org/10.1007/BF02072505

[8] Ozkan, H., Ozaksoy, D., Erçal, D., et al. (1996) Congenital Chylothorax. The Turkish Journal of Pediatrics, 38, 113-117.

[9] Altuncu, E., Akmam, I., Kryan, G., et al. (2007) Report of Tree Cases: Congenital Chylothorax and Treatment Modalities. The Turkish Journal of Pediatrics, 49, 418-421.

[10] Horvers, M., Mooij, C.F. and Antonius, T.A. (2012) Is Octreotide Treatment Useful in Patients with Congenital Chylothorax? Neonatology, 101, 225-231. http://dx.doi.org/10.1159/000330413

[11] Buttiker, V., Fanconi, S. and Burger, R. () Chylothorax in Children: Guidelines for Diagnosis and Management. Chest 116, 682-687. http://dx.doi.org/10.1378/chest.116.3.682

[12] Agawal, R., Khan, A., et al. (2012) Efficacy and Safety of Iodopovidone Pleurodesis: A Systematic Review and Meta-Analysis. Indian Journal of Medical Research, 135, 297-304.

[13] Noseda, C. and Putet, G. (2009) Chylothorax et hypothyroidie: A propos d'une observation. Archives de Pédiatrie, 16, 147-143. http://dx.doi.org/10.1016/j.arcped.2009.07.002 